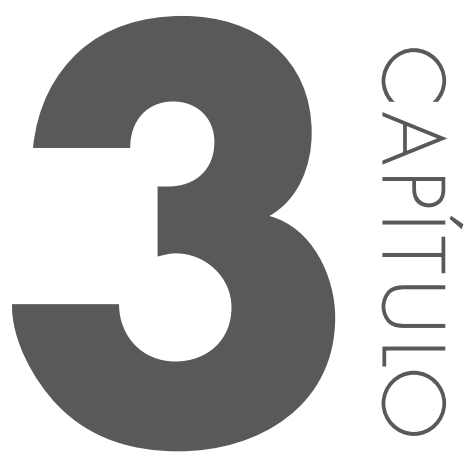

\title{
- MOdELO de campos e armas \\ DA COMPETIC̣ÃO EM ESTUDOS CIENTÍFICOS SOBRE ACADEMIAS: UMA ANÁLISE QUANTITATIVA
}

Camargo, Victor Hugo 1;

Gondim, Neiomar 1;

Hordones, Paulo Antônio 1 *

1 Programa de Pós-Graduação em Gestão Organizacional da Universidade Federal de Goiás/Catalão(PPGGO-UFG)

* email: ecn.pauloantonio@gmail.com 
Resumo: $\bigcirc$ conceito de estratégia competitiva vem sendo desenvolvido desde a década de 1950, por importantes autores internacionais, atualmente temos um modelo proposto por José Celso Contador que fundamenta a competitividade de empresas a partir de conceitos como campo e arma da competição. O presente estudo tem por objetivo avaliar do ponto de vista quantitativo e também qualitativo a utilização do modelo de campos e armas da competição em produções científicas sobre academias de modelo fitness no Brasil. A pesquisa justifica-se por entender que esse modelo de avaliação da competitividade de empresa, tem grande potencial de mensuração competitiva do mercado Fitness do Brasil . Metodologicamente foi proposto uma revisão que buscasse atender aos objetivos da pesquisa. Os resultados apontaram apenas dois estudos que abordavam o modelo de campos e armas de competitividade em academias. Conclui-se que pouca atenção tem sido dada por essa importante metodologia de avaliação estratégica em estudos sobre academias no Brasil. O modelo CAC se apresenta com um passo a frente nos métodos de avaliação de empresas, principalmente brasileiras e necessita ser melhor utilizado principalmente, no ramo de academias que vem crescendo substancialmente no país.

\section{Palavras-chave: Competitividade; Academia; fitness}




\section{Introdução}

Desde o surgimento do modo de produção capitalista a percepção e o desenvolvimento de novas relações entre a sociedade e os modelos de comercialização fizeram-se presentes no âmbito gerencial e econômico de diversas organizações, a disputa pela hegemonia de interesses do mercado evoluiu a um processo de competição que nos dias de hoje atinge uma parcela considerável dos esforços de boa parte das empresas do mundo. A grande verdade é que sobressaem em meio a essa batalha pela preferência do consumidor aquelas empresas que no intuito de aumentar seus rendimentos, o retorno sobre os recursos investidos e a estabilidade nos mercados em que atuam, buscam atingir e influenciar o seu consumidor de acordo 
com sua especificidade sócio-econômica, em outras palavras, avaliando, pesquisando e oferecendo o que ele precisa e deseja.

É quando lançamos mão de um conceito introduzido na sociedade entre os anos de 1957 e 1962 por nomes como Selzinick, Chandler, Learned et al. e Ansoff, o conceito que seria entendido anos depois como planejamento estratégico (CONTADOR, 2011). Ao longo das décadas a evolução desse ideal de pensamento proporcionou um movimento no que diz respeito ao referencial teórico da área que hoje percebemos ter sido de profunda relevância não só para gestores, como para pesquisadores do mundo inteiro. A década de 1970, por exemplo, foi notadamente o ponto de partida para o enfoque no planejamento estratégico, uma vez que foram conceituados expressões usualmente conhecidas no âmbito da gestão de negócios da atualidade, como planejamento tático, operacional e estratégico, ferramenta Swot e seus fundamentos como definição de negócio, visão, missão, valores. Nesse mesmo percurso a década de 1980 apresenta a diferenciação entre estratégia competitiva e vantagem competitiva, formulada por Porter a partir da consideração de fatores externos à organização (CONTADOR, 2011).

O enfoque de Porter nos fatores extra-organizacionais instigou o surgimento, nas décadas de 1980 e 1990, de um grupo de oposição a seus ideais, que acreditava estar nos fatores internos da empresa, a chave de uma boa vantagem competitiva, grupo esse que se confundia com a RBV (Resource Based View), modelo de rendimento concentrado nas capacidades e recursos controlados pela própria empresa (Barney 1986). Ainda na década de 1990 a conceituação de Balance Scorecard, uma metodologia de medida e desempenho criada por Robert Kaplan e David Norton, professores da Havard Business School, que utiliza quatro categorias de medidas, desempenho financeiro, conhecimento do cliente, processos internos, e aprendizado, norteou os métodos utilizados na área de gestão de negócios de parcela relevante da sociedade organizacional (KAPLAN, NORTON, 1992).

Adentramos finalmente na década de 2000 em que surge um modelo que propõe aliar os conceitos de Porter, da RBV e do Balance Scorecard (BSC), o modelo de campos e armas de competição (CAC), criado por José Celso Contador. O modelo CAC através dos critérios de diferenciação e ênfase no ambiente e nos fatores internos, busca aliar e integrar as duas concepções predominantes na teoria da estratégia competitiva, a concepção que entende a estratégia competitiva advindo fundamentalmente do posicionamento de mercado, e a concepção de que ela provém primordialmente de influenciantes internos (CONTADOR, 2008), além de alinhar as estratégias competitivas operacionais às estratégias internas de negócio como sugerido pelo BSC (KAPLAN, NORTON, 1992).

Em verdade, os conceitos de campos e armas da competição tiveram sua conceituação lançada pela primeira vez na literatura em 1995, pela revista de adminis- 
tração da USP (CONTADOR, 1995a; 1995b), passando por constante evolução desde então e chegando ao lançamento em um livro no ano de 2008 (CONTADOR, 2008). De acordo com o modelo de José Celso Contador, uma empresa define sua competitividade no mercado em que atua direcionando seus esforços nos interesses ou não do consumidor, ainda segundo o pesquisador, campos da competição referemse aos atributos que interessam ao cliente, como qualidade e preço do produto, e armas da competição é o caminho que a empresa utilizará para atingir vantagem competitiva, como marketing visual e pesquisa de mercado, mas que geralmente não possuem o interesse direto do consumidor (CONTADOR, 1995a; 1995b; GOMES, 2007; CONTADOR 2008; COSTA, 2008; GOMES, 2010; CONTADOR, 2011)

Diante de todo esse contexto o presente estudo terá por objetivo avaliar do ponto de vista quantitativo a utilização do modelo de campos e armas de competição em produções científicas sobre academias de modelo fitness no Brasil.

A pesquisa justifica-se por entender que um modelo de avaliação quantitativa e qualitativa, que estuda e explica o grau de competitividade de empresas, que foi criado por um autor brasileiro, tecendo assim mais fidedignidade às análises, tem grande potencial de mensuração competitiva do mercado Fitness do Brasil, mercado que possui um número de academias superior a $23 \mathrm{mil}$, representando mais da metade do número de unidades da América Latina e o apontado como o segundo maior em todo o mundo atrás apenas dos Estados Unidos (IHRSA Global Report 2013), mas que necessita de maior investigação e conceituação no âmbito científico.

Assim sendo, trata-se de um estudo de revisão, que não atende aos critérios quali/quantitativos rigorosos de uma revisão sistemática, nem fará um aprofundamento conceitual metodológico do modelo de campos, porém buscará analisar na literatura brasileira metodologias que abordaram o modelo de CAC.

\section{Metodologia}

Pelas características de uma pesquisa bibliográfica a operacionalização do estudo é de natureza qualitativa. Os estudos foram selecionados de duas formas distintas: para a primeira seleção utilizou-se a base de dados eletrônicas SCIELO - Scietific Electronic Library Online e para a segunda parte da seleção utilizou-se a base de dados Google Acadêmico, versão do Google para informações científicas. É oportuno esclarecer que a utilização do Google acadêmico em trabalhos científicos pode comprometer o impacto das publicações em situações em que não se conhece a metodologia de indexação dos arquivos em sua plataforma, uma vez que no ISI - Institute for Scientific Information - Thomson Scientific, entidade científica mundial que mede o impacto das publicações internacionais, as publicações passam por rigoroso 
processo de seleção, no Google Acadêmico todo conteúdo é bem vindo (MUGNAINI e STREHL. 2008). Em vista disso foram selecionados apenas estudos publicados em anais de congressos e simpósios científicos, além de revistas científicas com avaliação mínima no Qualis Capes, dissertações de mestrado e teses de doutorado.

As palavras chaves utilizadas nas pesquisas foram: modelo de campos e armas da competição, modelo de campos e armas da competição e academias, modelo de campos e armas da competição e empresas do ramo fitness, modelo de campos e armas da competição e empresas do mercado fitness. Inicialmente todos os estudos que apresentavam no título uma das palavras-chaves foram selecionados para leitura. Contudo, das 10 produções científicas listadas, somente 2 atendiam aos critérios de inclusão: estudos científicos que utilizassem o modelo de campos e armas da competição em academias ou empresas do ramo Fitness, quer fossem dissertações acadêmicas, quer fossem artigos publicados nas condições supracitadas. Os critérios de exclusão foram: artigos de opinião de especialista, artigos que não abordassem o ramo de academias e artigos que estivessem fora do padrão metodológico de um estudo científico. Os estudos científicos selecionados para essa revisão compreendem o período de 2009 a 2013.

$\mathrm{Na}$ análise da informação utilizaram-se procedimentos de análise de conteúdo, sendo que as categorias foram estabelecidas a priori: temática, contextos profissionais, instrumentos (coleta de dados), amostra e principais resultados.

\section{Resultados e Discussão de resultados}

As 2 produções selecionadas compreendem artigos nacionais publicados em revistas científicas ou anais de simpósios, sendo que 1 delas foi produzida a partir de uma dissertação de mestrado, veja o Quadro 1 abaixo.

Quadro 1. Sinopse dos estudos relativos à utilização do modelo CAC.

\begin{tabular}{|c|c|c|c|}
\hline $\begin{array}{l}\text { País/Autor/ Tipo } \\
\text { de Estudo }\end{array}$ & $\begin{array}{c}\text { Ano de } \\
\text { Publicação }\end{array}$ & $\begin{array}{l}\text { Objetivo/ Amostra/ } \\
\text { Instrumento } \\
\text { De coleta de dados }\end{array}$ & $\begin{array}{l}\text { Conclusões } \\
\text { Identificadas }\end{array}$ \\
\hline $\begin{array}{lr}\text { Brasil; } & \text { Corrêa, } \\
\text { Silvana } & \text { A. } \\
\text { Fartins, } \\
\text { Ferreira, } & \text { Ademir } \\
\text { Antônio; } & \text { Pesquisa }\end{array}$ & 2009 & $\begin{array}{l}\text { Verificar os fatores que } \\
\text { levam uma academia ser } \\
\text { mais competitiva que a outra; } \\
19 \text { empresas; } 3 \text { Questionários }\end{array}$ & $\begin{array}{l}\text { Academias mais } \\
\text { competitivas, } \\
\text { apresentam } \\
\text { equilíbrio na }\end{array}$ \\
\hline
\end{tabular}




\begin{tabular}{|c|c|c|c|}
\hline de Campo & & fechados. & $\begin{array}{l}\text { proporção } \\
\text { qualidade }=\text { preço } \\
\text { do produto. }\end{array}$ \\
\hline $\begin{array}{lr}\text { Brasil; } & \text { Pereira, } \\
\text { Renato } & \text { Zanuto, } \\
\text { Contador, } & \text { José } \\
\text { Celso, } & \text { Bazinini } \\
\text { Roberto, Estudo de } \\
\text { caso }\end{array}$ & 2013 & $\begin{array}{l}\text { Verificar se o modelo CAC } \\
\text { é suficiente para propor } \\
\text { estratégias competitivas que } \\
\text { aumentassem } \\
\text { competitividade de uma rede } \\
\text { de academias; } 1 \text { empresa; } \\
\text { Questionários fechados e } \\
\text { método popperiano } \\
\text { hipotético-dedutivo }\end{array}$ & $\begin{array}{l}\text { Constatou-se } \\
\text { suficiência do } \\
\text { processo, uma vez } \\
\text { que as propostas } \\
\text { apresentadas ao } \\
\text { proprietário foram } \\
\text { aceitas, levando à } \\
\text { aceitação da } \\
\text { hipótese. }\end{array}$ \\
\hline
\end{tabular}

Fonte: Dados da pesquisa.

Como se pode constatar no Quadro 1, a quantidade de estudos que abordam o modelo de campos e armas de competição em academias é verdadeiramente baixa, os dois estudos encontrados na literatura não utilizam o mesmo critério para definição dos objetivos, bem como também discordam na metodologia utilizada.

O instrumento de investigação na generalidade dos estudos foi o questionário, visto que as pesquisas foram fundamentadas a partir do modelo CAC, que utiliza primordialmente tal instrumento (CONTADOR, 2008). A amostra utilizada por Corrêa (2009) foi do tipo proposital e de maior número definindo maior representatividade para o estudo e fora escolhido um grupo que possuísse características de representação da população (MARCONI; LAKATOS, 1996), já para o estudo de Pereira (2013) a amostra escolhida foi do tipo intencional e de apenas uma empresa, caracterizando o tipo de pesquisa: Estudo de caso (OLIVEIRA, 1997).

Ao analisar o recorte cronológico dos estudos, constata-se um interesse pela temática apenas nos últimos anos, corroborando com a perspectiva de que se apresenta para a comunidade científica um novo âmbito de estudos na área de gestão.

Com base na objetividade do presente estudo observa-se que setor econômico escolhido possui ainda pouca abordagem na literatura quando o assunto é estratégias administrativas, uma justificativa pode se dar por este ser considerado um mercado relativamente jovem ainda, porém não menos importante e em constante evolução, como comprova a International Health Racquet e Sportsclub Association 
(IHRSA, 2011, p.24), maior entidade mundial responsável por representar as atividades de clubes, academias, SPAs e fornecedores fitness, autoridade em estudos econômicos e operacionais da área, ao afirmar que em 2011 a indústria do fitness obteve uma receita mundial de mais de US\$70 milhões, estando o Brasil inserido nessas cifras com mais de US\$ 2 bilhões. Outra justificativa pode se dar pela também relativa jovialidade do modelo de campos e armas de competitividade de Contador e seu complexo processo de avaliação (CONTADOR, 2008).

O modelo de campos e armas da competição possui em sua fundamentação metodológica uma característica peculiar, é considerado um modelo qualitativo e quantitativo, uma vez que define modelos quantitativos de análise estatística a partir de questionários conceituadamente qualitativos, fato esse que, na maioria dos casos, causa certo desconforto na comunidade científica, como detectou e discutiu, há anos atrás, Serapioni (2000), em seu trabalho que avaliava questões relacionadas ao uso de métodos quantitativos e qualitativos em pesquisa social na área da saúde. Este autor evidenciou a existência de preconceitos e falsos dilemas no debate sobre os métodos e propôs a superação da incomunicabilidade entre pesquisadores qualitativos e quantitativos.

Trabalhos de mesmo cunho metodológico dos encontrados na pesquisa como o de Pereira (2013), que investigassem a aplicabilidade do modelo de campos e armas de competição em empresas de outros setores também foram publicados, como a pesquisa de Passanezi e Contador (2011) que avaliou a aplicação do modelo CAC no setor de vendas de peças de concessionárias Chevrolet, detectando eficiência do modelo na avaliação competitiva da referida empresa. Outras pesquisas que utilizaram o modelo de campos e armas de competição em outros setores da economia já são apresentados há alguns anos e relatam, como estudos encontrados na presente pesquisa, boa eficiência do modelo em relação aos objetivos propostos, avaliação da competitividade estratégica de empresas (DE SORDI; CONTADOR, 2005; GOMES 2007; 2010; COSTA 2008; CONTADOR 2011,).

\section{Considerações Finais}

De acordo com os critérios metodológicos determinados neste estudo, é observado que o modelo de campos e armas de competição, que desde sua proposição vem sendo incorporado em pesquisas sobre empresas de alguns dos setores da economia, ainda não adentrou no campo teórico do mercado fitness, ou o mercado de academias, o que evidencia grande necessidade de esforços acadêmicos para que rapidamente essa lacuna investigativa seja suprimida. $O$ mercado fitness vem crescendo rapidamente nos últimos anos e naturalmente haverá a necessidade de acom- 
panhamento do campo teórico/científico, que hoje, mesmo em outras instâncias de pesquisa que não as deste estudo, possui uma abordagem deficitária e incompleta. Um novo campo de estudo vem se apresentando sob essa perspectiva e teóricos das áreas de administração, marketing, educação física etc. tendem a possuir diversos questionamentos sobre a área em questão. $O$ modelo $C A C$ se apresenta com uma passo a frente nos métodos de avaliação de empresas, principalmente brasileiras, e necessita ser melhor utilizado principalmente, no ramo de academias que vem crescendo substancialmente no país. 


\section{The model fields and Weapons competition in Scientific Studies Gyms : A Quantitative Analysis .}

Abstract: The concept of competitive strategy has been developed since the 1950 s by leading international authors, we currently have one proposed by Contadoor model that underlies the competitiveness of companies from the field and weapon concepts like the competition. The present study was designed to evaluate the quantitative point of view and also the qualitative use of weapons and field competition model in scientific production on fitness gyms in Brazil. The research is warranted to understand that this evaluation model of enterprise competitiveness, has great potential for measuring the competitive fitness market in Brazil. Methodologically proposed a revision that seek to meet the research objectives. The results showed only two studies that addressed the model fields and weapons of competitiveness in gyms. We conclude that little attention has been given by this important strategic assessment methodology in studies of gyms in Brazil. The CAC model is presented with a step forward in the evaluation methods of companies, mainly Brazilian and needs to be better utilized primarily in the business of gyms that has grown substantially in the country.

Keywords: Competitive Strategy, Competitive Advantage, Gyms Strategy.

\section{REFERÊNCIAS BIBLIOGRÁFICAS}

BARNEY, J. Strategic factor markets: expectations, luck, and business strategy. Management Science, v.32, n. 10, p.1231-1241, $1986^{\mathrm{a}}$

CONTADOR, J. C. Metodologia para formulação da estratégia competitiva de manufatura: Um enfoque quantitativo. Revista Base (Administração e Contabilidade) da UNISINOS [online] 2011.

Formulação da estratégia competitiva para micro e pequenas empresas por meio do modelo de campos e armas de competição. Revista da micro e pequena empresa. v. 1, n. 1, p. 38-53, 2011.

Conceitos sobre o modelo de campos e armas da competição. Revista de Ciências da Administração, v. 10, n. 21, p. 147-174, 2008.

Armas da competição. Revista de Administração da USP, São Paulo, 30 (2), 50-64, abr/ junho 1995. 
Campos da competição. Revista de Administração da USP, São Paulo, 30 (1), 32-45, jan/ mar 1995.

COSTA, M. A. M.; SANCHES, C.; MARIETTO, M. L.; SILVA, O. R. Campos e armas da competição: um modelo para formular estratégia de produção nas pequenas e médias empresas. Revista de Administração e lnovação, v. 4, n. 3, p. 102-116, 2007.

CORREA, S. A. M. ; FERREIRA, A. A. . Estratégia competitiva das academias de ginástica da cidade de São Paulo. FACEF Pesquisa, v. 12, p. 63-76, 2009.

DE SORDI, J. O.; CONTADOR, J. C. Integração dos sistemas de informação à estratégia da organização por meio do modelo de campos e armas da competição. Revista de Administração, São Paulo, v. 40, n. 2, p. 123-135, abr./jun. 2005.

GOMES, L. S. Proposta de um sistema de suporte executivo para micro e pequenas empresas fundamentado no modelo campos e armas da competição. Revista Produção Online, v. 10, n. 4, p. 861-885, 2010.

Micro e pequenas empresas: especificações dos requisitos funcionais de um software para formulação estruturada de estratégias competitivas fundamentada no modelo de campos e armas da competição. 2007. Dissertação (Mestrado) - UNINOVE, São Paulo, 2007.

IHRSA. The Ihrsa Global report 2013. Boston: IHRSA 2013. Disponível em: hHtp://www.ihrsa.org/latinamercia-report. Consultado em: 09/11/2014.

IHRSA. The Ihrsa Global report 2011. Boston: IHRSA 2011. Disponível em: http://download.ihrsa.org/ pubs/2011_HHRSA_International_Report_TOC.pdf. Consultado em: 09/11/2014.

KAPLAN, Robert S., NORTON, David P.- The Balanced Scorecard - Measures that Drive Performance Harvard Business Review, Boston v.70 - n. 1 - p.71-79 - jan/feb, 1992.

MARCONI, M. D. A.; LAKATOS, E. M. Técnicas de pesquisa: planejamento e execução de pesquisas, amostragens e técnicas de pesquisas, elaboração, análise e interpretação de dados. 3.ed. São Paulo: Atlas, 1996.

MUGNAINI, R., STREHL, L. Recuperação e impacto da produção cientifica na era Google: uma análise comparativa entre o Google Acadêmico e a Web of Science. Encontros Bibli: R. Eletr. Bibliotecon. Ci. Inf., Florianópolis, p. 92-105, $1^{\circ}$ sem. 2008. Número Especial.

OLIVEIRA, S. L. Tratado de metodologia científica: Projetos de Pesquisas, TGI, TCC, monografias, dissertações e teses. São Paulo: Pioneira, 1997. 
PASSANEZI, P. M. S.; CONTADOR, J. C. Metodologia de campos e armas da competição aplicada ao estudo da competitividade de concessionárias Chevrolet. Revista de Negócios, v. 16, n. 2, p. 65-85, $2011 .$.

PEREIRA, R. Z. CONTADOR, J. C. BAZANINI, R. Revista lbero-Americana de Estratégia - RIAE, São Paulo, v. 12, n. 3, p. 242-280, jul./set. 2013.

SERAPIONI, Mauro. Métodos qualitativos e quantitativos na pesquisa social em saúde: algumas estratégias para a integração. Ciência \& Saúde Coletiva, v. 5, n. 1, p. 187-192, 2000. 